\title{
CARACTERÍSTICAS E PROPRIEDADES DO KEFIR
}

\author{
Heloysa Maria Sottoriva \\ Dhara Ribeiro Melo ${ }^{1}$ \\ Taiara Cristina Fenner Matias ${ }^{2}$ \\ Aline Aparecida Furioso ${ }^{2}$ \\ Lucas Piauí dos Santos ${ }^{2}$ \\ Gilberto Alves ${ }^{3}$
}

SOTTORIVA, H. M.; MELO, D. R.; MATIAS, T. C. F.; FURIOSO, A. A.; SANTOS, L. P. dos; ALVES, G. Características e propriedades do kefir. Arq. Ciênc. Vet. Zool. UNIPAR, Umuarama, v. 21, n. 4, Anais do II Concivet 2018, p. 141-142, out./ dez. 2018.

RESUMO: Pode-se definir kefir como sendo um complexo produto lácteo fermentado produzido por fermentação do leite por bactérias ácido láticas e leveduras contidos dentro de um complexo de exopolissacarídeo e proteínas denominado de grão de kefir. Embora não seja tão popular mundialmente como outros produtos lácteos fermentados ele tem apresentado nos últimos anos um aumento de consumo devido, principalmente, ao seu conteúdo de bactérias probióticas e seus benefícios à saúde. O objetivo desse trabalho foi apresentar as principais características e propriedades do kefir e os benefícios de seu consumo. A composição de microrganismos nos grãos de kefir é muito variável e complexa, uma vez que depende da sua origem, condições de crescimento e manutenção, mas sabe-se que há a predominância de bactérias ácido-láticas, acéticas, leveduras e fungos. O principal polissacarídeo encontrado nos grãos de kefir é o kefirano, um heteropolissacarídeo composto por iguais proporções de glicose e galactose e que possui propriedades antitumorais, antifúngicas, antibacteriana, anti-inflamatória e antioxidante. Devido a essas características, muitos produtos estão sendo desenvolvidos empregando kefir como cultura lática, como queijos, labneh, bebidas à base de extrato de soja e chás fermentados. O uso do kefir como um alimento funcional está aumentando dia a dia em todo o mundo e, assim tendo um maior interesse da comunidade científica por se tratar de um alimento funcional de baixo custo, mas também com várias aplicações na indústria de alimentos sendo desenvolvidas.

PALAVRAS-CHAVE: Alimentos funcionais. Kefirano. Probióticos.

\section{CHARACTERISTICS AND PROPERTIES OF KEFIR}

\begin{abstract}
Kefir can be defined as a complex fermented dairy product produced by fermentation of milk by lactic acid bacteria and yeasts contained within a exopolysaccharide and protein complex known as kefir grain. Although it is not as popular worldwide as other fermented dairy products, its consumption has increased in recent years, mainly due to its probiotic bacteria and the health benefits it provides. This work aims at describing the main characteristics and properties of kefir as well as the benefits of its consumption. The microorganism composition in kefir grains is very variable and complex, since it depends on their origin, growth and maintenance conditions, but it is known to present predominantly lactic and acetic acid, as well as yeast and fungal bacteria. The main polysaccharide found in kefir grains is known as kefiran, a heteropolysaccharide comprised of equal proportions of glucose and galactose. It presents antitumor, antifungal, antibacterial, anti-inflammatory and anti-oxidant properties. Due to these characteristics, many products are being developed using kefir as lactic acid culture, such as cheeses, labneh, soy-based drinks and fermented teas. The use of kefir as functional food is increasing worldwide, and therefore, there is a great interest of the scientific community due to it not only being a functional, low-cost food, but also due to several applications in the food industry being developed with it.
\end{abstract}

KEYWORDS: Functional foods. Kefiran. Probiotics.

\section{CARACTERÍSTICAS Y PROPIEDADES DEL KÉFIR}

RESUMEN: Se puede definir kéfir como un complejo producto lácteo fermentado producido por fermentación de la leche por bacterias ácidos lácticos y levaduras contenidas dentro de un complejo de exopolisacárido y proteínas denominado de grano de kéfir. Aunque no es tan popular mundialmente como otros productos lácteos fermentados, ha presentado en los últimos años un aumento de consumo debido principalmente a su contenido de bacterias probióticas y sus beneficios a la salud que proviene. El objetivo de este estudio fue presentar las principales características y propiedades del kéfir y los beneficios de su consumo. La composición de microorganismos en los granos de kéfir es muy variable y compleja, ya que depende de su origen, condiciones de crecimiento y mantenimiento, pero se sabe que hay predominio de bacterias ácidos lácticos, acéticos, levaduras y hongos. El principal polisacárido encontrado en los granos de kéfir es el kefirano, un heteropolisacárido compuesto por iguales proporciones de glucosa y galactosa y que tiene propiedades antitumorales, anti fúngicas, antibacterianas, antiinflamatorias y antioxidantes. Debido a esas características, muchos productos están siendo desarrollados empleando kéfir como cultura láctica, como quesos, labneh, bebidas a base de extracto de soja y tés fermentados. El uso del kéfir como

DOI: 10.25110 /arqvet.v21i4.2018.7340

${ }^{1}$ Acadêmica do curso de Medicina Veterinária da Universidade Paranaense (UNIPAR).

${ }^{2}$ Acadêmico do curso de Nutrição (UNIPAR).

${ }^{3}$ Docente dos cursos de Medicina Veterinária e Nutrição da Universidade Paranaense (UNIPAR), gilberto.alimentos@prof.unipar.br. 
alimento funcional está aumentando día a día en todo el mundo y así teniendo un mayor interés de la comunidad científica por tratarse de un alimento funcional de bajo costo, así como varias aplicaciones en la industria de alimentos están siendo desarrolladas.

PALABRAS CLAVE: Alimentos funcionales. Kefirano. Probióticos. 